\title{
HIV Testing Practices among Men Who Have Sex with Men in Buenos Aires, Argentina
}

\author{
Alex Carballo-Diéguez, Ph.D. ${ }^{1}$, Iván C. Balán, Ph.D. ${ }^{1}$, Curtis Dolezal, Ph.D. ${ }^{1}$, María A. \\ Pando, Ph.D. ${ }^{2}$, Rubén Marone, Lic. ${ }^{3}$, Victoria Barreda, Lic. ${ }^{3}$, and María Mercedes Ávila, \\ Ph.D. ${ }^{2}$ \\ ${ }^{1}$ HIV Center for Clinical and Behavioral Studies, New York State Psychiatric Institute and \\ Columbia University, New York, United States
}

${ }^{2}$ Centro Nacional de Referencia para el SIDA, Departamento de Microbiología, Parasitología e Inmunología, Facultad de Medicina, Universidad de Buenos Aires, Buenos Aires, Argentina

${ }^{3}$ Nexo Asociación Civil, Buenos Aires, Argentina

\section{Abstract}

The objective of the study was to explore HIV-testing practices among MSM in Buenos Aires, Argentina, in light of current international health guidelines that recommend frequent HIV testing for MSM who engage in high-risk behavior. Participants, who were recruited using respondentdriven sampling (RDS), were 500 mostly young, non-gay-identified MSM of low socioeconomic status, high levels of unemployment, living mainly in the less affluent areas surrounding Buenos Aires, and lacking health insurance. They provided blood samples for HIV testing and responded to a Computer Assisted Self Interview. Fifty-two percent had never been tested for HIV, and 20\% had been tested only once; $17 \%$ were found to be HIV infected, of whom almost half were unaware of their status. Main reasons for never having tested previously were: not feeling at risk, fear of finding out results, and not knowing where to get tested. Among those previously tested, men had been tested a median of 2 times with their most recent test having occurred a median of 2.7 years prior to study enrollment. Of those who had not tested positive before entering the study, only $41 \%$ returned for their results. HIV testing was infrequent and insufficient for early detection of infection, entry into treatment, and protection of sexual partners. This was particularly the case among non-gay-identified MSM. Testing campaigns should aim to help MSM become aware of their risk behavior, decrease fear of testing by explaining available treatment resources and decreasing the stigma associated with HIV, and by publicizing information about free and confidential testing locations. Rapid HIV testing should be made available to eliminate the need for a return visit and make results immediately available to individuals who are tested.

\section{Keywords}

HIV prevalence; gay; respondent-driven sampling; MSM

\section{Introduction}

Regular HIV testing facilitates early detection of infection among at-risk individuals, and early HIV detection is directly associated with improved clinical outcomes and decreased sexual risk behavior (Oberzaucher \& Baggaley, 2002; Weinhardt, Carey, Johnson, \&

All correspondence and reprint requests should be sent to Alex Carballo-Diéguez, Ph.D., Unit 15, New York State Psychiatric Institute, 1051 Riverside Drive, NY, New York 10032, USA, phone +1-212-543-5261, fax +1-212-543-6003, ac72@columbia.edu. 
Bickham, 1999; World Health Organization, 2004). Early and successful treatment of HIVinfected individuals with antiretrovirals (ARVs), significantly decreases the chances of HIV transmission to partners. A study involving mainly heterosexual serodiscordant couples showed that this decrease was $96 \%$ (Cohen et al., 2011); to date, no comparable data are available for men who have sex with men (MSM).

The US Centers for Disease Control and Prevention (CDC; 2010; 2011) recommend testing every three to six months for sexually active MSM. Given that large percentages of HIVinfected persons are unaware of their infection (MacKellar et al., 2006; Sifakis et al., 2010), especially among MSM who remain at disproportionate risk of infection (Adam et al., 2009; Sumartojo et al., 2008), frequent testing is important. Although the percentage of MSM who have never tested for HIV is decreasing (Helms et al., 2009), many MSM remain untested or test infrequently (CDC, 2011; Guy et al., 2010; MacKellar et al., 2006; Manning et al., 2007). Likelihood and frequency of testing may be related to demographic characteristics such as sexual identity, age and ethnicity (Nelson et al., 2010; Sifakis et al., 2010; Wei et al., 2011); and to fear of positive results, perceived HIV risk, and beliefs about HIV treatment (Kellerman et al., 2002; Mikolajczak, Hospers, \& Kok, 2006; Song et al., 2011).

Most of the research on frequency of HIV testing has occurred in the U.S., Europe, Australia, and China. Little is known about the frequency of HIV testing among Latin American MSM and the factors that facilitate or impede testing among this population. In Argentina, which has an estimated 134,000 HIV-infected individuals (Ministerio de Salud, 2011) and where the government provides free HIV treatment, regular HIV testing among high-risk populations could significantly impact HIV mortality and prevention efforts. MSM, whose HIV prevalence and incidence rates in the city of Buenos Aires are $17.3 \%$ and 4.53 per 100 person-years respectively (Pando et al., 2011), could benefit greatly from frequent testing.

We aim to contribute to the understanding of HIV testing among MSM in Latin America by reporting on a sample of 500 demographically diverse MSM from Buenos Aires, Argentina (additional results in Balan et al., 2011; Barreda et al., 2010; Carballo-Diéguez, Ávila, et al., 2011; Carballo-Diéguez, Balan, et al., 2011; Pando et al., 2012; Pando et al., 2011). We explored HIV testing history, patterns, reasons for testing or not, and the association of these variables with demographic characteristics and sexual identity.

\section{Materials and Methods}

\section{Ethics Statement}

The Institutional Review Boards of the New York State Psychiatric Institute, USA, and la Facultad de Medicina, Universidad de Buenos Aires, Argentina, approved this study.

\section{Participants}

Recruitment took place through respondent-driven sampling (RDS; Heckathorn, 1997, 2002) a method for both data collection and statistical inference. In RDS, a few participants ("seeds") are recruited to participate in the study and to invite three others from their network to enroll as well. Participants give coupons to those they invite who can then also recruit people from their networks until the target number is reached. Participants are offered dual incentives (for participation and for each person they recruit) thus producing chains of referrals that move away from the initial seeds. Participants report the number of people in their network who belong to the target population; this number is used to weight the data. This weighting strategy distinguishes RDS from simple snowball sampling. Although RDS is purportedly better than snowball sampling to reach more representative samples of hidden populations, one drawback is that it tends to cluster cohesive 
subpopulations (Goel \& Salganik, 2010). Also, by nature, RDS allows for selection bias, as peers invited to participate may screen themselves out without ever making contact with the recruitment staff.

Eligibility criteria for our study were to identify as a man, be at least 18 years old, have had sex with another man or a transgender woman (TGW; male-to-female) in the prior six months, have had sex with a man or TGW at least 10 times in his lifetime (to exclude individuals with infrequent occasions), reside in Buenos Aires or its environs, have received a coupon from a prior participant (not applicable to seeds), and agree to provide a blood sample for HIV and STI testing.

\section{Procedure}

A detailed description of the use of RDS in this study has been published elsewhere (Carballo-Diéguez, Balan, et al., 2011). Briefly, 16 socioeconomically diverse seeds were recruited, underwent all study procedures, and were given three coupons (valid for 60 days) to pass on to members of their networks. In total, 500 MSM (our target sample by study design) were recruited from November 2007 through July 2009 and seen at the offices of Nexo Asociacion Civil, our non-governmental organization (NGO) partner. Men who met eligibility criteria provided written consent and answered a password-protected, Web-based, computer-assisted self-interview (CASI) that inquired, among other topics, about demographic information, sexual identity, and HIV testing history. Participants who did not feel comfortable using a computer could ask for assistance from a research assistant who then read the questions verbatim and entered the participant's responses.

Next, blood was drawn for HIV and other STI testing (additional results and prevalence of other STIs appear in Pando et al., 2012). HIV pre-test counseling was provided to all participants, and post-test counseling to those who received their results. Finally, the research assistant administered the Social Network Assessment (described below), handed the participants three coupons, encouraged each participant to "give the coupons to people like you," and took contact information to notify participants when they could redeem compensation for participant referral. Altogether, the interviews lasted from two to three hours, each participant receiving the equivalent of 20 US dollars (price of five movie tickets) as compensation for his time. For each referred acquaintance who qualified for the study, regardless of whether he enrolled or not, participants received US\$ 5 .

\section{Instruments}

Demographics-The structured questionnaire covered age, education, income, work status, residence, civil status and health insurance.

Sexual Identity-Participants indicated whether they considered themselves 1) gay/ homosexual, 2) bisexual, 3) transvestite (in Buenos Aires, the term transvestite rather than transgender is frequently used), 4) heterosexual, or 5) other. The study was not designed to include transgender persons; those identifying as such were deemed ineligible to participate.

Social Network-To determine the participant's social network size, we asked: 1) "Approximately, how many men who have sex with other men and/or transvestites do you know personally?" 2) "Of those men, how many do you know by name, who they are, and how to contact them?" 3) "Of those men, how many also know you?" 4) "Of these men, with how many have you been in contact in the past six months? Contact may be face-toface, by phone, or email." 5) "Of those men, how many live in Buenos Aires?" 6) "Of those men, how many are 18 years or older?" 7) "Of these men, how many might be willing to participate in this study?" 8) "Who gave you the coupon to participate in this study (study 
personnel, friend, partner, family member, workmate, someone unknown, other)?" We used question 7 to measure network size for RDS weighting purposes.

HIV testing history-We inquired whether participants had tested for HIV previously, reasons for never testing, assumptions about status among those not tested, reasons for first testing among those tested, and frequency of testing for those with more than one test.

HIV test-HIV diagnosis was assessed using ELISA and agglutination techniques and confirmed by Western Blot at the Centro Nacional de Referencia para el SIDA (CNRS), Facultad de Medicina, Universidad de Buenos Aires.

\section{Statistical analysis}

All data have been weighted based on reported network size. The weighting estimator is based on the RDS II estimator (Volz \& Heckathorn, 2008). More details on this analytic strategy are reported elsewhere (Carballo-Diéguez, Balan, et al., 2011). Statistical analyses were conducted using PASW Statistics ${ }^{\circledR}$ (SPSS Inc, 2009). Participants were classified by sexual identity and by HIV testing prior to study participation (Y/N). Four- and two-group comparisons were conducted using chi-square tests for dichotomous/categorical variables and t-tests or ANOVAs for continuous variables.

\section{Results}

\section{Sample}

Of the 500 MSM in the sample, $24.5 \%$ identified as gay, $36.2 \%$ as bisexual, $21.9 \%$ as heterosexual, and $17.4 \%$ as other. Those responding as "other" tended to be younger and of lower education level. They provided labels such as "hombre" (man), "macho," and "activo" (active) that did not allow clear assignment to any of the other three categories.

Table 1 presents the demographic characteristics of the sample by sexual identity. Participants' mean age was 30.5 (SD 11.5); almost half of participants were 18-25 years old, with gay-identified men being older on average than non-gay men. Two-thirds had not completed high school; lower levels of education were reported by the non-gay-identified men. Twenty-nine percent had no income; non-gay-identified men earned less than gayidentified men. Almost one-third of participants were unemployed, and a similar proportion only had temporary work (categories could overlap). Twenty-nine percent of participants resided in Ciudad Autonoma de Buenos Aires (Buenos Aires proper, the Capital city), while the majority of participants came from the less affluent suburbs of the West Zone and South Zone. Most participants were single (same sex marriage was legalized in Argentina after recruitment for this study was concluded). Four out of 5 participants had no private or employer-supported health insurance (and probably relied on public hospital services); gays were more likely to have employer-supported health insurance. In sum, this was a sample of young, mostly single, non-gay-identified MSM, of low socioeconomic status (especially among the non-gay-identified), high levels of unemployment, living mainly in the less affluent areas surrounding Buenos Aires, and mainly lacking health insurance.

\section{HIV testing}

Table 2 shows the HIV testing history of the sample. About half of participants had never been tested for HIV; one-fifth had been tested only once. Gay-identified men reported the highest rates of HIV testing. There was a significantly higher proportion of tested individuals among those with only one partner in the prior two months than among those with multiple partners $\left(77 \%\right.$ vs. $44 \%, \mathrm{X}^{2}=17.3, \mathrm{df}=1, \mathrm{p}<.001$ ). Laboratory results of HIV tests conducted as part of our study showed an overall HIV prevalence of $17 \%$. Fifty-six 
percent of individuals who tested HIV positive in the study were already aware of their status, and $4 \%$ reported previous AIDS diagnoses. By contrast, $44 \%$ of individuals were unaware of their infection until they were tested during our study. Those who had been tested before entering the study had their last test done a median of 2.7 years before (range, 1 month to 27 years). Twelve percent reported being tested in the past year, and an additional 30\% reported being tested in the past 2 years. Forty percent reported that their most recent test was 4 or more years ago. The 4 sexual identity groups did not significantly differ on time since last HIV test.

Table 3 shows the reasons for not testing among those never tested before. The most frequent reasons for not testing were low risk perception, fear of learning the results, and/or not knowing where to get tested. More gay than non-gay-identified men reported not knowing where to get tested and cost as a reason for not testing. These gay men were significantly younger and had lower incomes than gay men who had been previously tested.

Table 4 shows the reasons for testing among those tested before joining the study. Almost half of the men claimed their primary reason was simply to know if they were infected; $19 \%$ were tested as part of a physical exam. Only 16\% reported having been tested because of unprotected sex. Thirteen percent said testing was required by their employers (this was more common among non-gay-identified men). Five percent got tested because they were experiencing symptoms, and all but one of these participants was HIV infected.

Among those tested, the median number of testing occasions was 2 (not shown in the tables). HIV testing confirmed the self-reported HIV status of $89 \%$ of individuals with discrepancies in the remaining $11 \%$ (7\% of participants assumed being HIV-negative but were found to be infected; $4 \%$ of participants assumed being infected but were actually uninfected).

Test results were available for participants about two weeks following sample collection. After weighting, 181 (41\% of 442) of those who had not previously tested HIV-positive returned to the testing site for their results. Gay men were more likely to return for their results than non-gay-identified men $\left(59 \%\right.$ vs. $\left.36 \%, X^{2}=16.14, \mathrm{df}=1, \mathrm{p}<.001\right)$.

Table 5 presents the associations of demographic variables and HIV testing history. No prior HIV testing was associated with younger age, lower education and income, being unemployed (and inversely related to being self-employed or a student), living in the less affluent areas of the city (West and South zones), being single, having no health insurance, and having a smaller network size.

\section{Discussion}

In this RDS-recruited MSM sample, HIV testing was infrequent and insufficient for early detection of infection, entry into treatment, and protection of sexual partners. This was particularly the case among non-gay-identified MSM. Almost half of HIV-infected participants were unaware of their status and consequently not in treatment and potentially infectious to partners.

Several measures could be taken to counteract this situation. Testing campaigns could be aimed to help MSM, particularly those not gay identified, to become more aware of the behaviors that put them at risk. Given the observed variations in likelihood and frequency of HIV testing according to sexual identity, HIV testing campaigns should highlight that regardless of sexual or gender identity, individuals who engage in sexual risk behavior should be tested regularly. Furthermore, the finding that only $16 \%$ reported having been tested because they had unprotected sex is interesting considering that, as previously 
reported (Carballo-Diéguez, Balan, et al., 2011), 88\% of participants had had more than one sexual partner in the past two months, with a median of 5.8 (SD 13.13) unprotected anal or vaginal intercourse occasions (range 0-200). This finding suggests low risk perception in this population despite apparently high levels of risk behavior.

Fear of testing could be decreased by disseminating information on currently available treatments for those found to be infected. Publicizing information about free and confidential testing locations may further increase testing, particularly for those concerned about costs; this measure would be particularly important in view of the high percentage of participants without health insurance and who relied instead on public hospitals. Although Argentina offers health coverage to all citizens, services may be uneven, crowded, or lacking resources, which may dissuade some people from seeking HIV testing at a hospital. The availability of dedicated free services, like those provided by an NGO, could facilitate access to testing. Furthermore, including HIV testing in regular physical exams, both in private and public settings, could increase both the number of individuals and the frequency of testing.

Developing campaigns to decrease HIV-associated stigma could facilitate test-seeking behaviors. With its legalization of same-sex marriage, Argentina became a leader in Latin America in its quest to decrease sexual-orientation-based discrimination. Lessons learned through that process should be applied to further erode stigmatization of HIV.

The observation that only $41 \%$ of individuals who had not tested positive before returned to the clinic for their test results is in sharp contrast with that of prior studies conducted in Buenos Aires with mainly gay-identified MSM. Pando et al. (2003), reported that in their studies, $96.2 \%$ of the participants returned to the NGO for their test results and post-test counseling. Given that participants who had referred other men to the study could collect an incentive when they returned to the testing site, the proportion of participants in our study who received their results could potentially have been even lower in the absence of the incentive. Although none of the participants expressly refused to get their test results, a few said they did not have time or that they would return later, which may have been subterfuges to avoid learning of the results. The failure by many participants to receive HIV test results supports the benefit of using rapid HIV testing so that results can be delivered in the same session (Balán et al., 2011). Currently, rapid HIV tests that can provide results in about 20 minutes are not widely used in Buenos Aires where typically people must wait several days for their test results. Rapid HIV tests should be made available in Buenos Aires promptly.

Finally, the association of lack of prior HIV testing with sociodemographic indicators of social marginalization (lower education and income, unemployment, no health insurance, fewer social connections) indicates an urgent need to promote and facilitate HIV testing among the most disenfranchised sectors of the greater Buenos Aires population.

This study has several limitations. Except for laboratory results, all our data consist of selfreports. Thus, they are subject to inaccuracy due to poor recall and voluntary or involuntary distortion. Furthermore, RDS can perform poorly when traits cluster in cohesive subpopulations, a phenomenon that may be especially acute in the case of infectious diseases (Goel \& Salganik, 2010). Our sampling procedure largely failed to attract volunteers from the north (more affluent) zone of Buenos Aires, which is consequently underrepresented in these results. This may be a result of bottlenecks in the network structure of the population (Goel \& Salganik, 2009, 2010). Yet, within these constraints the results of this investigation with a diverse sample of $500 \mathrm{MSM}$ provide guidelines for orienting HIV testing efforts that could counteract further spread of the epidemic. 


\section{Acknowledgments}

This study was supported by the US National Institute of Mental Health through R01-MH073410 (PI: Alex Carballo-Diéguez, Ph.D.) and P30-MH43520 (PI: Anke A. Ehrhardt, Ph.D.).

\section{References}

Adam PC, de Wit JB, Toskin I, Mathers BM, Nashkhoev M, Zablotska I, Rugg D, et al. Estimating levels of HIV testing, HIV prevention coverage, HIV knowledge, and condom use among men who have sex with men (MSM) in low-income and middle-income countries. Journal of Acquired Immune Deficiency Syndromes. 2009; 52(Suppl 2):S143-151.10.1097/QAI.0b013e3181baf111 [PubMed: 19901627]

Balán I, Carballo-Diéguez A, Marone R, Pando M, Barreda V, Ávila MM. Aceptabilidad del diagnóstico rápido para HIV entre hombres gay y otros hombres que tienen sexo con hombres (G\&HSH) de la ciudad de Buenos Aires [Acceptability of rapid HIV testing among gay and other men who have sex with men in Buenos Aires, Argentina]. Actualizaciones en SIDA. 2011; 19(71): 26-32.

Barreda V, Carballo-Dieguez A, Marone R, Balan I, Pando MA, Avila MM. Prevencion del VIH/ SIDA en los circuitos de levante HSH: una asignatura pendiente [HIV/AIDS prevention in MSM cruising sites: an unfinished assignment]. Sexualidad, Salud y Sociedad: Revista Latinoamericana. 2010; (6):41-62.

Carballo-Diéguez A, Ávila M, Balán I, Marone R, Pando M, Barreda V. Presentación del estudio "Links" de hombres que tienen sexo con hombres en Buenos Aires, Argentina [Overview of the "Links" study on men who have sex with men in Argentina]. Actualizaciones en SIDA. 2011; 19(71):21-25.

Carballo-Diéguez A, Balan I, Marone R, Pando MA, Dolezal C, Barreda V, Ávila MM, et al. Use of respondent driven sampling (RDS) generates a very diverse sample of men who have sex with men (MSM) in Buenos Aires, Argentina. PLoS ONE. 2011; 6(11):e27447.10.1371/journal.pone.0027447 [PubMed: 22102896]

Centers for Disease Control and Prevention. HIV among gay, bisexual and other men who have sex with men (MSM). 2010 Sep 23. Retrieved November 17, 2011[website] from http://www.cdc.gov/ hiv/topics/msm/

Centers for Disease Control and Prevention. HIV testing among men who have sex with men--21 cities, United States, 2008. Morbidity and Mortality Weekly Report. 2011; 60:694-699. [PubMed: 21637183]

Cohen MS, Chen YQ, McCauley M, Gamble T, Hosseinipour MC, Kumarasamy N, Fleming TR, et al. Prevention of HIV-1 infection with early antiretroviral therapy. New England Journal of Medicine. 2011; 365:493-505.10.1056/NEJMoa1105243 [PubMed: 21767103]

Goel S, Salganik MJ. Respondent-driven sampling as Markov chain Monte Carlo. Statistics in Medicine. 2009; 28(17):2202-2229.10.1002/sim.3613 [PubMed: 19572381]

Goel S, Salganik MJ. Assessing respondent-driven sampling. Proceedings of the National Academy of Sciences. 2010; 107(15):6743-6747.10.1073/pnas.1000261107

Guy R, Goller JL, Spelman T, El-Hayek C, Gold J, Lim M, Hellard M, et al. Does the frequency of HIV and STI testing among men who have sex with men in primary care adhere with Australian guidelines? Sexually Transmitted Infections. 2010; 86:371-376.10.1136/sti.2009.040972 [PubMed: 20460263]

Heckathorn DD. Respondent-driven sampling: a new approach to the study of hidden populations. Social Problems. 1997; 44:174-199.10.2307/3096941

Heckathorn DD. Respondent-driven sampling II: deriving valid population estimates from chainreferral samples of hidden populations. Social Problems. 2002; 49:11-34.10.1525/sp.2002.49.1.11

Helms DJ, Weinstock HS, Mahle KC, Bernstein KT, Furness BW, Kent CK, Golden MR, et al. HIV testing frequency among men who have sex with men attending sexually transmitted disease clinics: implications for HIV prevention and surveillance. Journal of Acquired Immune Deficiency Syndromes. 2009; 50:320-326.10.1097/QAI.0b013e3181945f03 [PubMed: 19194309] 
Kellerman SE, Lehman JS, Lansky A, Stevens MR, Hecht FM, Bindman AB, Wortley PM. HIV testing within at-risk populations in the United States and the reasons for seeking or avoiding HIV testing. Journal of Acquired Immune Deficiency Syndromes. 2002; 31:202-210.10.1097/01.QAI. 0000024005.76120.97 [PubMed: 12394799]

MacKellar DA, Valleroy LA, Anderson JE, Behel S, Secura GM, Bingham T, Janssen RS, et al. Recent HIV testing among young men who have sex with men: correlates, contexts, and HIV seroconversion. Sexually Transmitted Diseases. 2006; 33:183-192.10.1097/01.olq. 0000204507.21902.b3 [PubMed: 16508526]

Manning SE, Thorpe LE, Ramaswamy C, Hajat A, Marx MA, Karpati AM, Nash D, et al. Estimation of HIV prevalence, risk factors, and testing frequency among sexually active men who have sex with men, aged 18-64 years--New York City, 2002. Journal of Urban Health. 2007; 84:212225.10.1007/s11524-006-9135-5 [PubMed: 17295058]

Mikolajczak J, Hospers HJ, Kok G. Reasons for not taking an HIV-test among untested men who have sex with men: an Internet study. AIDS and Behavior. 2006; 10:431-435.10.1007/ s10461-006-9068-8 [PubMed: 16501868]

Ministerio de, Salud. Boletín sobre el VIH-SIDA en la Argentina [Bulletin on HIV-AIDS in Argentina] (No 28. Año XIV). 2011. Retrieved from: http://www.msal.gov.ar/sida/pdf/boletinesinves-publi/boletin-epidemiologico-2011.pdf

Nelson KM, Thiede H, Hawes SE, Golden MR, Hutcheson R, Carey JW, Jenkins RA, et al. Why the wait? Delayed HIV diagnosis among men who have sex with men. Journal of Urban Health. 2010; 87:642-655.10.1007/s11524-010-9434-8 [PubMed: 20186493]

Oberzaucher, N.; Baggaley, R. HIV voluntary counselling and testing: a gateway to prevention and care. 2002. (UNAIDS/02.41E). Retrieved from: http://data.unaids.org/Publications/IRC-pub02/ JC729-VCT-Gateway-CS_en.pdf

Pando MA, Maulen S, Weissenbacher M, Marone R, Duranti R, Peralta LM, Ávila MM, et al. High human immunodeficiency virus type 1 seroprevalence in men who have sex with men in Buenos Aires, Argentina: risk factors for infection. International Journal of Epidemiology. 2003; 32:735740.10.1093/ije/dyg104 [PubMed: 14559741]

Pando MA, Balan IC, Marone R, Dolezal C, Leu C-S, Squiquera L, Avila MM, et al. HIV and other sexually transmitted infections among men who have sex with men recruited by RDS in Buenos Aires, Argentina: high HIV and HPV infection. PLoS ONE. 2012; 7(6):e39834.10.1371/ journal.pone.0039834 [PubMed: 22768137]

Pando, MA.; Marone, R.; Balan, I.; Dolezal, C.; Barreda, V.; Carballo-Diéguez, A.; Avila, MM. P15.02. Circumcision and HIV acquisition risk among men who have sex with men (MSM) in Buenos Aires, Argentina. Poster presented at AIDS Vaccine 2011; Bangkok, Thailand. 2011. p. A78

PASW Statistics (Version 18) [Computer software]. Chicago, IL: SPSS Inc;

Sifakis F, Hylton JB, Flynn C, Solomon L, MacKellar DA, Valleroy LA, Celentano DD. Prevalence of HIV infection and prior HIV testing among young men who have sex with men. The Baltimore young men's survey. AIDS and Behavior. 2010; 14:904-912.10.1007/s10461-007-9317-5 [PubMed: 17968648]

Song Y, Li X, Zhang L, Fang X, Lin X, Liu Y, Stanton B. HIV-testing behavior among young migrant men who have sex with men (MSM) in Beijing, China. AIDS Care. 2011; 23:179_ 186.10.1080/09540121.2010.487088 [PubMed: 21259130]

Sumartojo E, Lyles C, Choi K, Clark L, Collins C, Grey CG, Remafedi G, et al. Prevalence and correlates of HIV testing in a multi-site sample of young men who have sex with men. AIDS Care. 2008; 20:1-14.10.1080/09540120701450425 [PubMed: 18278609]

Volz E, Heckathorn DD. Probability based estimation theory for respondent driven sampling. Journal of Official Statistics. 2008; 24:79-97.

Wei C, Ruan S, Zhao J, Yang H, Zhu Y, Raymond HF. Which Chinese men who have sex with men miss out on HIV testing? Sexually Transmitted Infections. 2011; 87:225-228.10.1136/sti. 2010.047407 [PubMed: 21270068] 
Weinhardt LS, Carey MP, Johnson BT, Bickham NL. Effects of HIV counseling and testing on sexual risk behavior: a meta-analytic review of published research, 1985-1997. American Journal of Public Health. 1999; 89:1397-1405. [PubMed: 10474559]

World Health Organization. Rapid HIV tests: guidelines for use in HIV testing and counselling services in resource-constrained settings. 2004. Retrieved from: http://www.emro.who.int/aiecf/ web28.pdf 


\begin{tabular}{|c|c|c|c|c|c|c|c|c|c|c|c|c|c|}
\hline \multirow{2}{*}{ 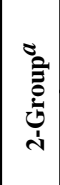 } & 2 & 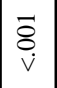 & $\underset{v}{\vec{s}}$ & ڤి. & है & $\underset{v}{\vec{\delta}}$ & $\begin{array}{l}\infty \\
ٌ \\
\sigma\end{array}$ & 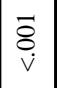 & $\begin{array}{c}\widehat{D} \\
\infty \\
0\end{array}$ & $\begin{array}{l}\bar{\Xi} \\
\dot{v}\end{array}$ & $\stackrel{\circ}{\circ}$ & $\ddot{b}$ & $\underset{v}{\bar{\delta}}$ \\
\hline & $\underset{\Sigma}{*}$ & 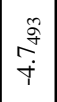 & 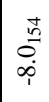 & $\stackrel{n}{-}$ & 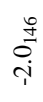 & $\begin{array}{l}\bar{n} \\
\stackrel{y}{I}\end{array}$ & $\stackrel{5}{0}$ & $\overrightarrow{\mathrm{i}}$ & $\stackrel{-}{\circ}$ & $\begin{array}{l}\stackrel{ }{I} \\
\end{array}$ & $\stackrel{2}{2}$ & $\stackrel{-}{-}$ & $\begin{array}{l}\vec{\sigma} \\
\dot{\sigma}\end{array}$ \\
\hline \multirow{2}{*}{ 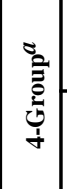 } & $=$ & $\begin{array}{l}\vec{\delta} \\
\dot{v}\end{array}$ & 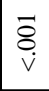 & छे. & $\stackrel{\circ}{\circ}$ & $\tilde{\delta}$ & $\hat{s}$ & $\begin{array}{l}\vec{\delta} \\
\dot{v}\end{array}$ & $\stackrel{n}{\curvearrowleft}$ & $\begin{array}{l}\vec{\delta} \\
\dot{v}\end{array}$ & $\tilde{\delta}$ & ర్ & $\underset{\dot{v}}{\bar{\delta}}$ \\
\hline & $\frac{x^{*}}{x_{x}^{*}}$ & $\stackrel{f}{\sigma}$ & $\frac{m}{2}$ & $\dot{m}$ & $\stackrel{\infty}{\infty} \underset{\infty}{\infty}$ & $\stackrel{m}{\stackrel{m}{g}}$ & $\stackrel{m}{\stackrel{m}{r}}$ & $\mid \begin{array}{c}\tilde{c} \\
\infty \\
\sim \\
\sim\end{array}$ & $\stackrel{\mathscr{c}}{\stackrel{9}{\leftrightarrows}}$ & $\begin{array}{l}\stackrel{\infty}{\sim} \\
\stackrel{\sim}{\sim}\end{array}$ & ֻ̊ & $\stackrel{?}{\Omega}$ & $\stackrel{?}{\vec{q}}$ \\
\hline
\end{tabular}

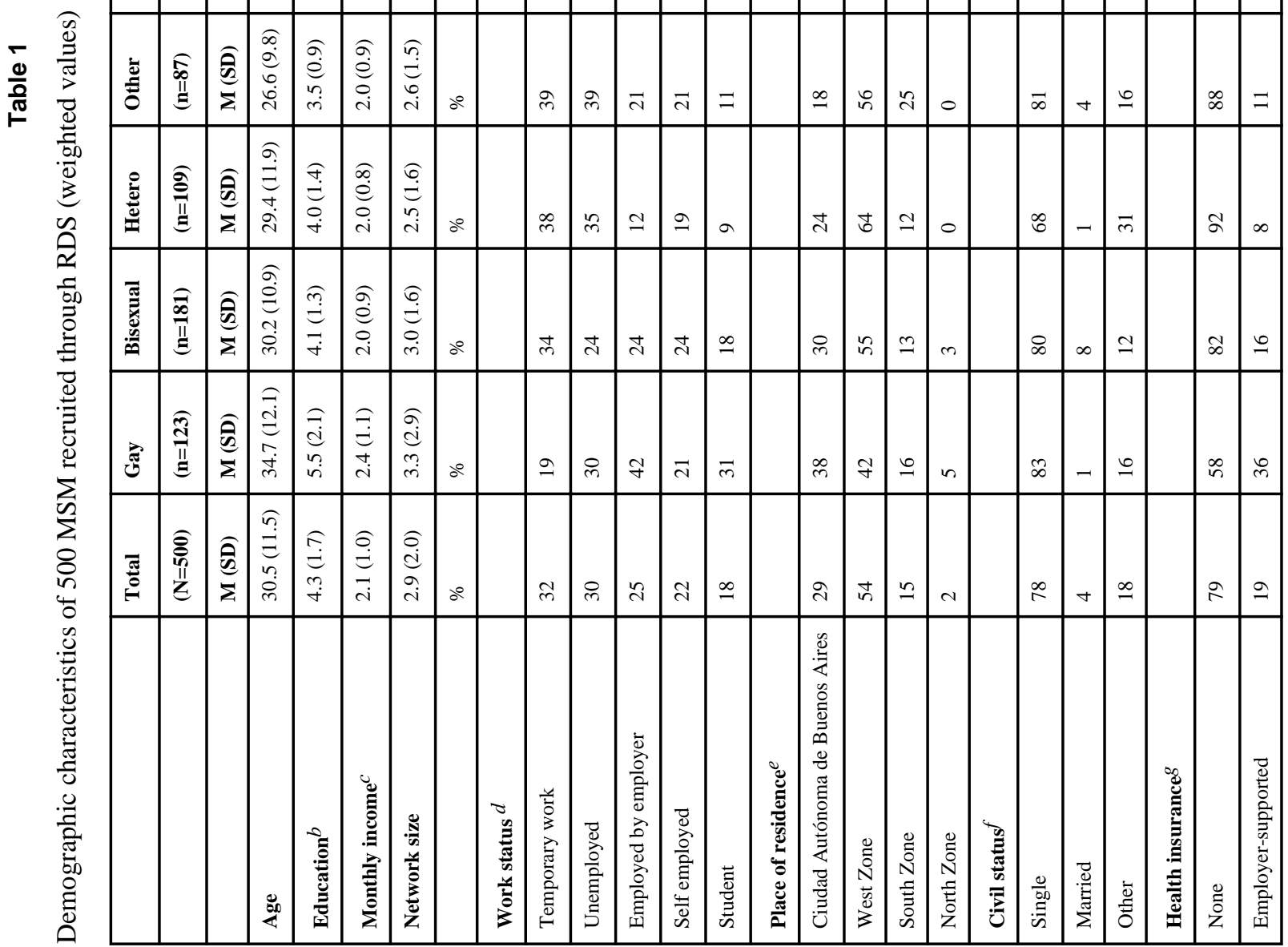




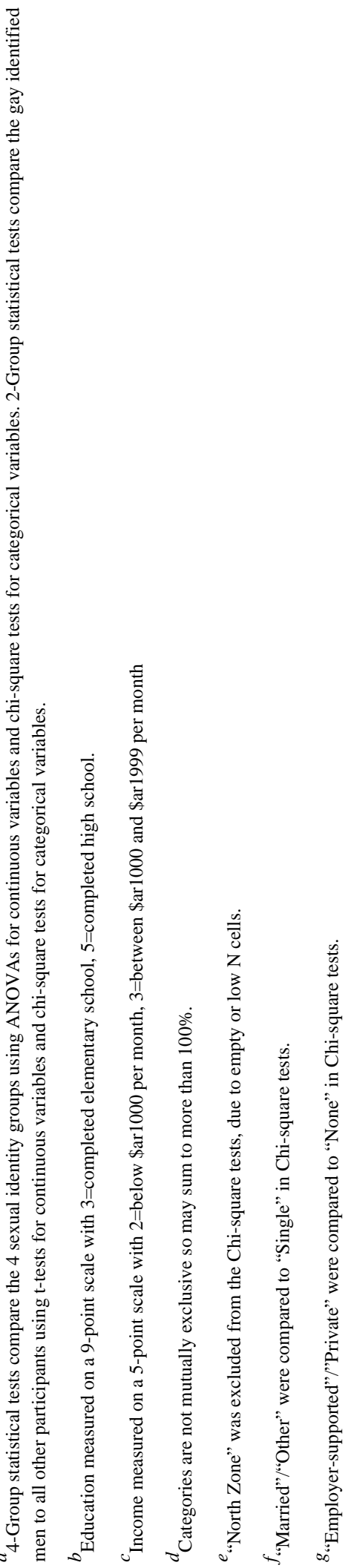




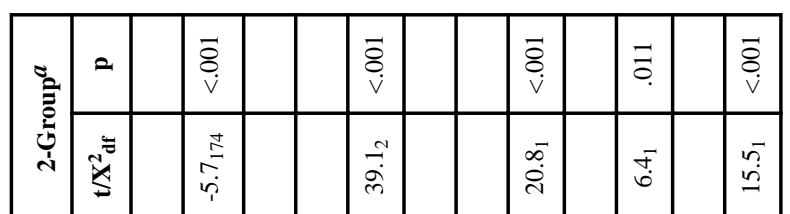

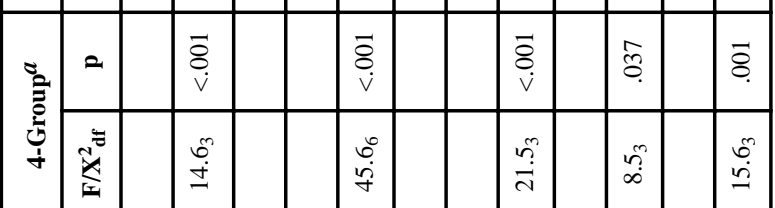

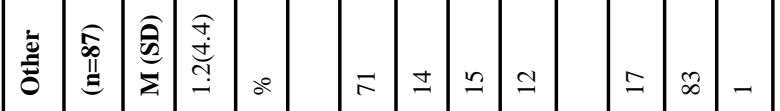

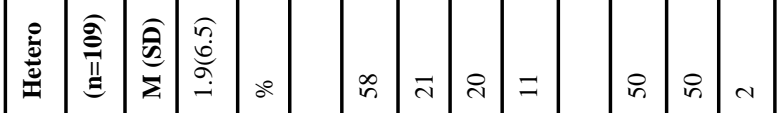

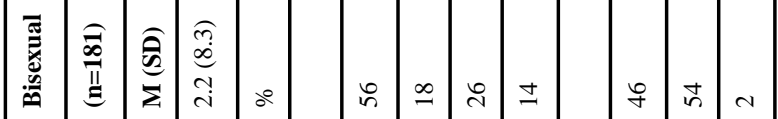

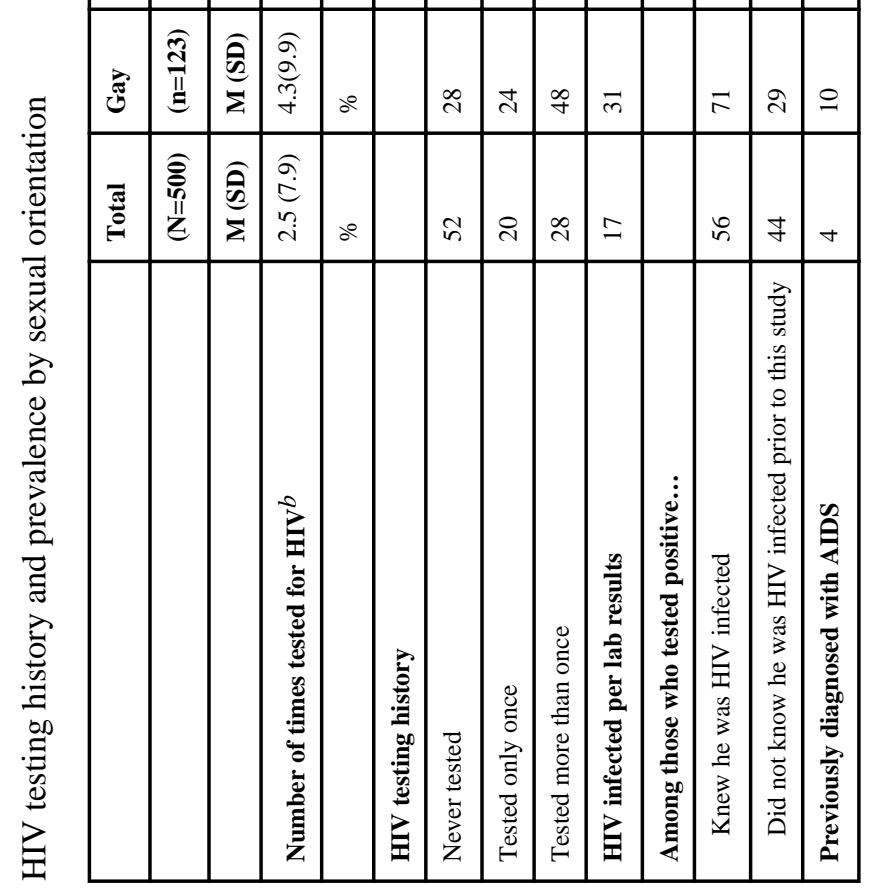




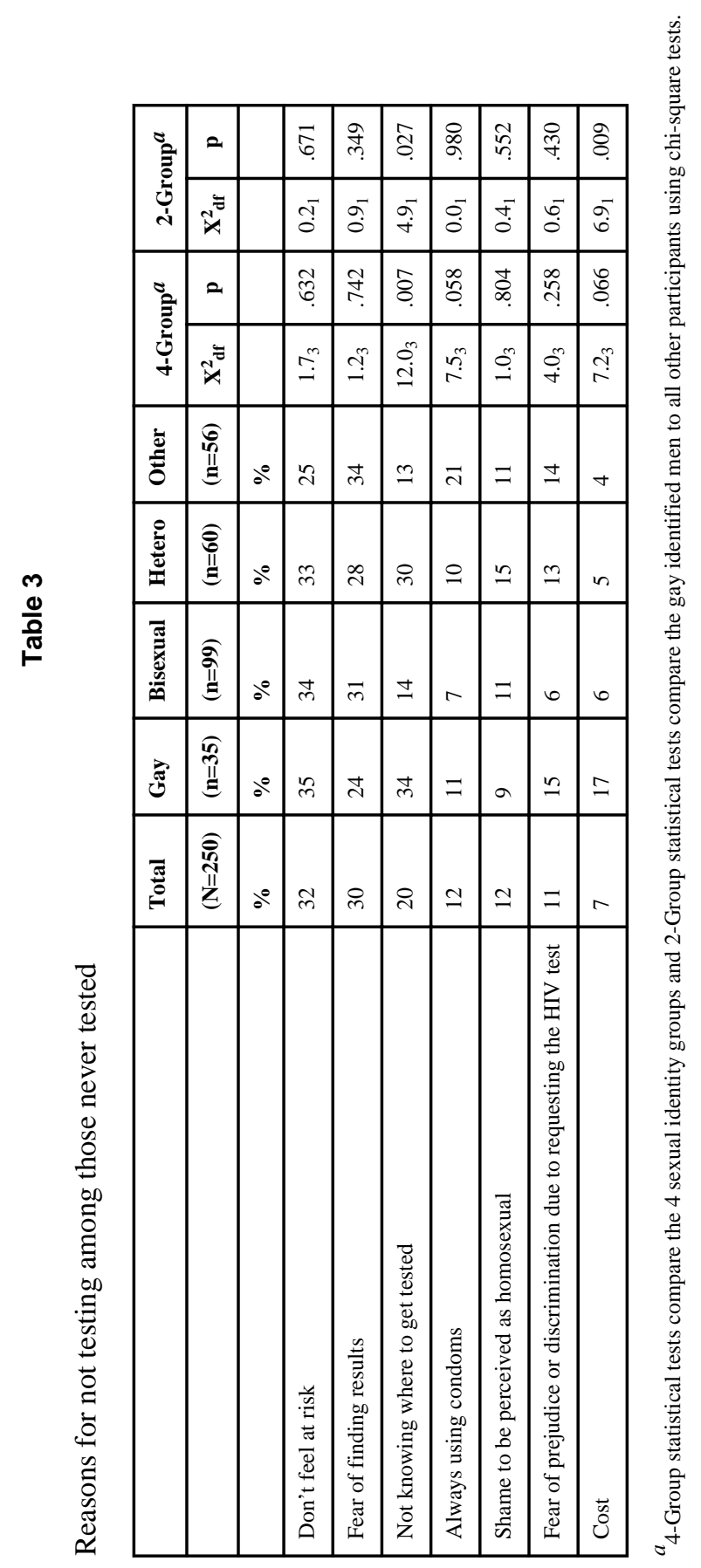

AIDS Care. Author manuscript; available in PMC 2015 January 01. 


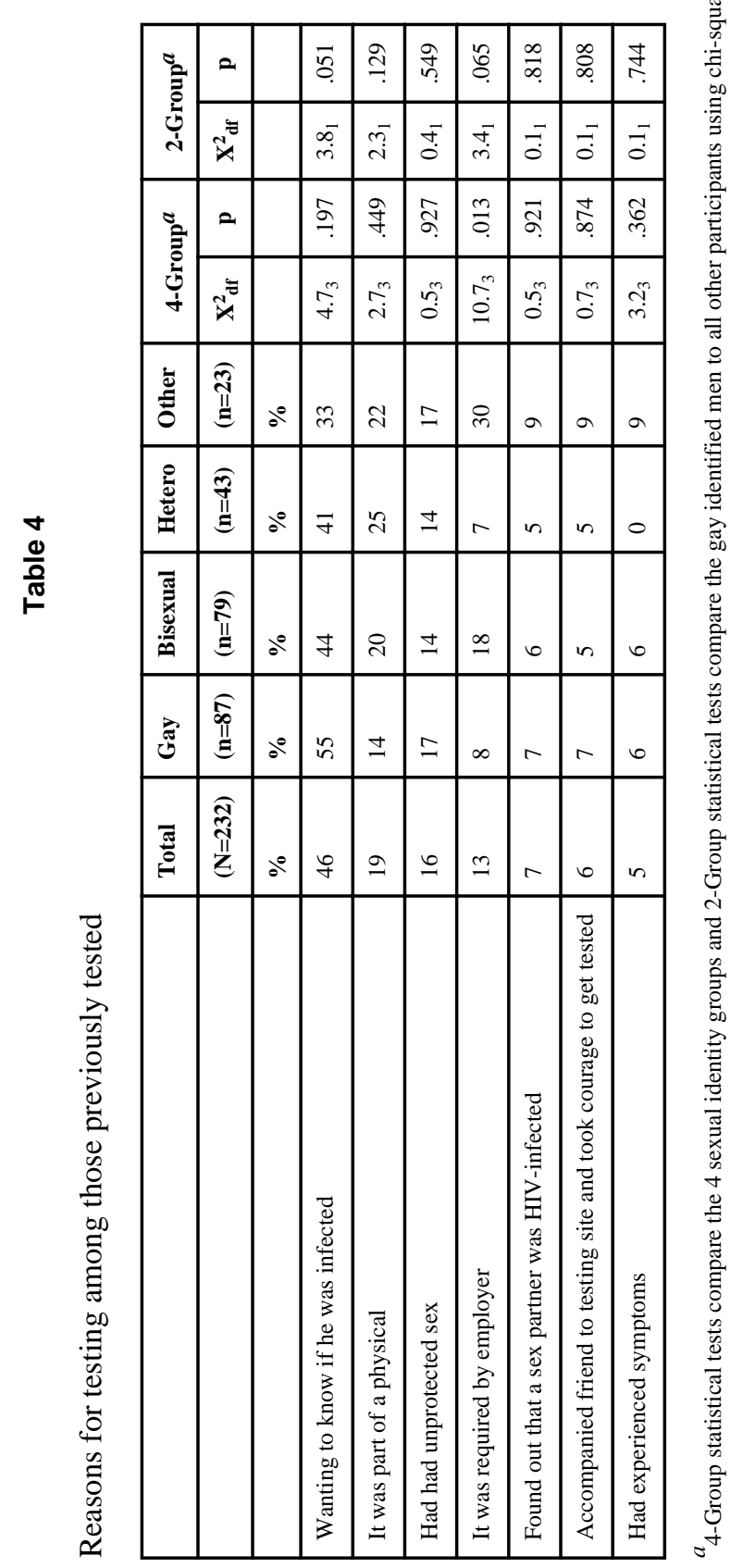

AIDS Care. Author manuscript; available in PMC 2015 January 01. 
Table 5

Demographic differences based on prior HIV testing history

\begin{tabular}{|c|c|c|c|c|}
\hline & No prior HIV test $(\mathrm{N}=250)$ & Prior HIV test $(\mathrm{N}=232)$ & $\mathrm{t}_{\mathrm{df}} / \mathrm{Beta} / \mathrm{OR}^{a}$ & $\mathbf{p}$ \\
\hline & $\mathbf{M}(\mathbf{S D})$ & $\mathbf{M}(\mathbf{S D})$ & & \\
\hline Age & $27.5(10.9)$ & $34.1(11.4)$ & $-6.5_{480}$ & $<.001$ \\
\hline Education $^{b}$ & $4.0(1.4)$ & $4.7(1.9)$ & 0.18 & $<.001$ \\
\hline Monthly income ${ }^{c}$ & $1.9(0.8)$ & $2.3(1.0)$ & 0.14 & .005 \\
\hline \multirow[t]{2}{*}{ Network size } & $2.6(1.8)$ & $3.2(2.1)$ & 0.15 & .002 \\
\hline & $\% d$ & $\% d$ & & \\
\hline \multicolumn{5}{|l|}{ Work status ${ }^{e}$} \\
\hline Temporary work & 32 & 30 & 0.91 & .655 \\
\hline Unemployed & 37 & 25 & 0.67 & .055 \\
\hline Employed by employer & 22 & 28 & 1.42 & .115 \\
\hline Self employed & 17 & 28 & 1.59 & .047 \\
\hline Student & 15 & 22 & 0.41 & .001 \\
\hline Place of residence $f$ & & & 0.68 & .046 \\
\hline Ciudad Autónoma de Buenos Aires & 22 & 37 & & \\
\hline West Zone & 58 & 48 & & \\
\hline South Zone & 19 & 12 & & \\
\hline North Zone & 1 & 4 & & \\
\hline Civil status $g$ & & & 0.78 & .290 \\
\hline Single & 83 & 73 & & \\
\hline Married & 2 & 6 & & \\
\hline Other & 15 & 21 & & \\
\hline Health insurance ${ }^{h}$ & & & 2.17 & .001 \\
\hline None & 86 & 71 & & \\
\hline Employer-supported & 13 & 25 & & \\
\hline Private & 1 & 4 & & \\
\hline
\end{tabular}

${ }^{a}$ Statistical tests are from linear or logistic regressions, adjusting for age (except for age itself, which is a t-test).

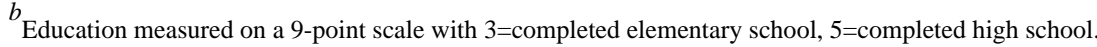

${ }^{c}$ Income measured on a 5-point scale with 2=below \$ar1000 per month, 3=between $\$ \operatorname{ar} 1000$ and $\$$ ar1 1999 per month.

${ }^{d}$ Percentages do not always sum to 100 due to rounding.

${ }^{e}$ Categories are not mutually exclusive so may sum to more than $100 \%$.

$f_{\text {Statistical test is West Zone vs. other. }}$

${ }^{g}$ Statistical test is single vs. married/other.

${ }^{h}$ Statistical test is insured vs. not. 